Archive for

Organic Chemistry

Arkivoc 2018, part v, 0-0

\title{
Synthesis of novel bis(nicotinecarbonitrile) derivatives
}

\author{
Ali M. S. Hebishy, ${ }^{2}$ Ismail A. Abdelhamid, ${ }^{1}$ and Ahmed H. M. Elwahy ${ }^{1 *}$ \\ ${ }^{1}$ Chemistry Department, Faculty of Science, Cairo University, Giza-Egypt \\ ${ }^{2}$ Chemistry Department, Faculty of Science, Helwan University, Cairo-Egypt \\ Email: aelwahy@hotmail.com
}

Received 10-17-2018

Accepted 03-15-2018

Published on line 06-07-2018

\section{Abstract}

A series of bis(nicotinecarbonitriles) were prepared via the reaction of bis arylidenemalononitriles with acetophenone in ethanolic potassium hydroxide solution. The isomeric bis(nicotinecarbonitriles) could also be obtained by the reaction of arylidenemalononitriles with bis acetophenone under similar conditions. The reaction was assumed to take place via Michael addition followed by cyclization due to the alkoxide nucleophilic attack at one of the nitrile groups. Alternative syntheses of both isomeric derivatives were also reported.
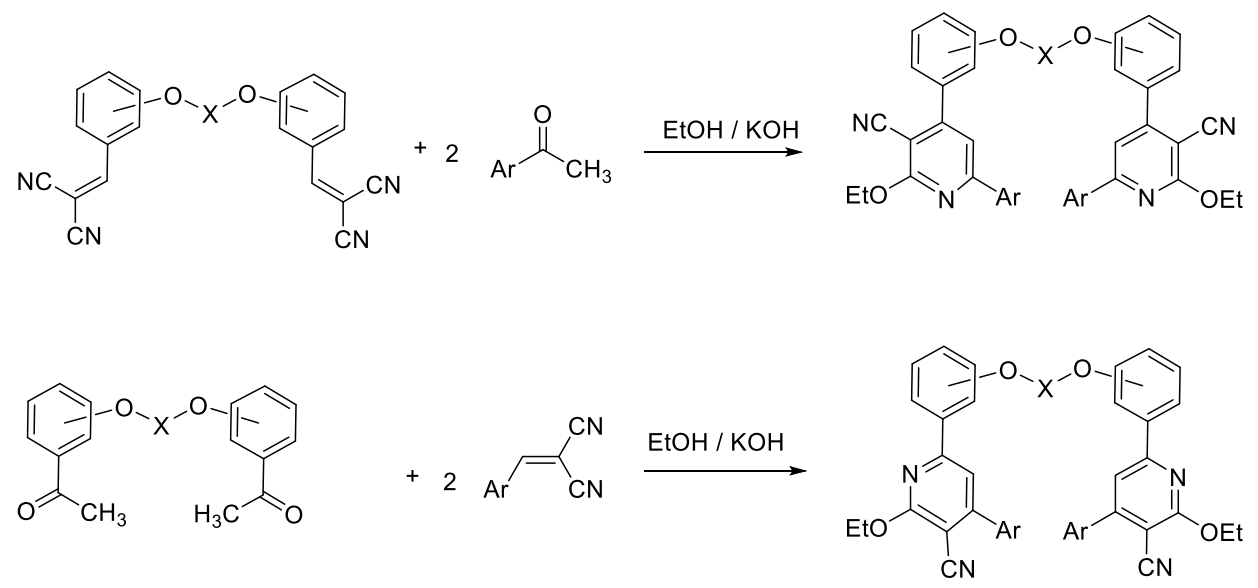

Keywords: Bis(nicotinecarbonitriles), bis(arylidenemalononitriles), bis(chalcones), Michael addition, cyclization 


\section{Introduction}

Pyridine derivatives are an important class of azaheterocycle found in many natural products. They have occupied a unique position in the field of medicinal chemistry (cf. Figure 1$)^{1}$ due to their wide range of biological and pharmacological activities ${ }^{2-9}$. In this respect, some pyridine derivatives have been reported to exhibit antibacterial $^{10}$, antimicrobial ${ }^{11,12}$, antifungal ${ }^{13}$, cardiotonic $^{14}$, analgesic ${ }^{15}$, antiinflammatory ${ }^{16}$ and anti-lung cancer ${ }^{17}$ activities. Alternatively, some pyridine derivatives also represent the most interesting heterocyclic units in some agrochemical targets (cf. Figure 2) ${ }^{18-20}$.

Due to the continued importance of the pyridine core in both biological and chemical fields, different methodologies for pyridine synthesis have been developed ${ }^{21-24}$. Among them, one-pot multicomponent reactions, remain the most interesting one in the synthesis of pyridine as well as different heterocycles and natural products ${ }^{25-29}$. Modification of such strategies continues to be an interesting theme in literature. As a consequence of this interest and in continuation of our work on Michael addition ${ }^{30-37}$, multicomponent reactions ${ }^{33-36,38-44}$ as well as on the synthesis of bis-heterocyclic with a suitable spacer ${ }^{40,44-54}$, we report herein the results of our investigations concerning the synthesis of novel bis(nicotinecarbonitrile) derivatives.

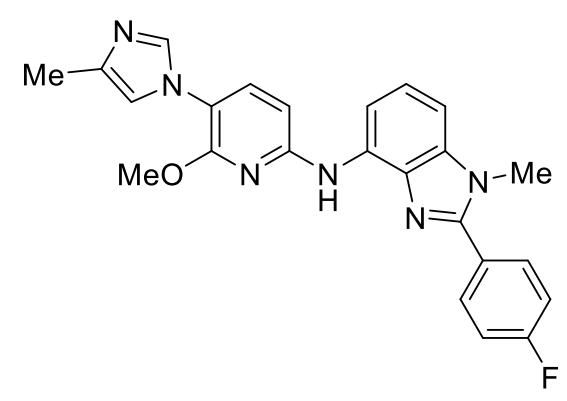

$\gamma$-Secretase modulator

Treatment of Alzheimer's disease

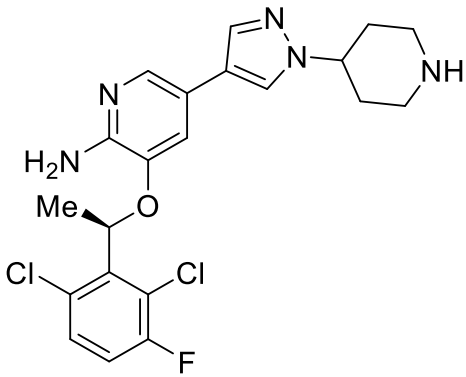

Crizotinib (Xalkori, pfizer) Treatment of lung cancer

Figure 1<smiles>COc1cc(CCCc2ccccc2)ccn1</smiles>

Antifungul<smiles>CCOC(=O)c1c(N)nc(Oc2cccc(C)c2[N+](=O)[O-])c(C#N)c1N</smiles>

Herbicide<smiles>O=[N+]([O-])/N=C1\NCCN1Cc1ccc(Cl)nc1</smiles>

Insecticide

Figure 2

\section{Results and Discussion}

Firstly, we studied the attempted synthesis of bis pyridines 4 via a four-component reaction of bis aldehydes $\mathbf{1}^{33,39}$, malononitrile $\mathbf{2}$, acetopheone derivatives $\mathbf{3 a - c}$ and $\mathrm{NH}_{4} \mathrm{OAc}$ in refluxing ethanol (Scheme 1). 


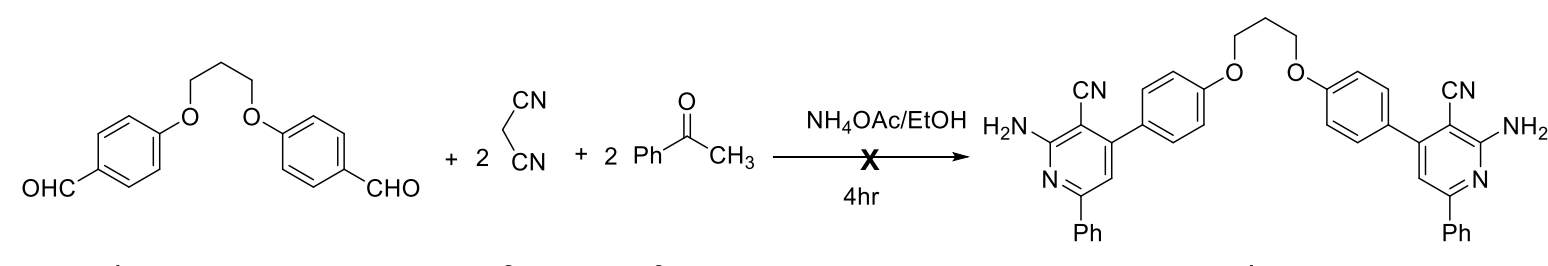

$1 \mathrm{a}$

2

3a

4a

\section{Scheme 1}

Unfortunately, under these conditions we could not isolate a pure sample of the corresponding bis pyridine 4. The reaction instead gave a product that was not easily handled and has not been characterized as yet. The reaction is assumed to proceed firstly via two-component reaction between the bis aldehyde $\mathbf{1}$ and malononitrile 2 to give a desired intermediate bis-arylidene-malononitrile $5^{33,39}$ which then subsequently reacts with acetophenone $\mathbf{3 a}$ in the presence of ammonium acetate to give $\mathbf{4}$ (Scheme 2 ).

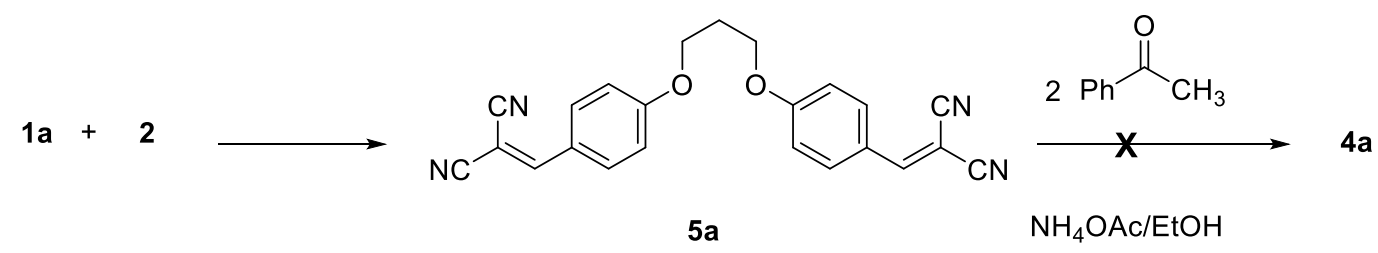

\section{Scheme 2}

The reaction may also proceed via firstly formation of chalcone $6^{55}$ by condensing 1 with acetophenone 3 . The pyridine was assumed to be formed by the reacting of 6 with malononitrile in the presence of ammonium acetate (Scheme 3).

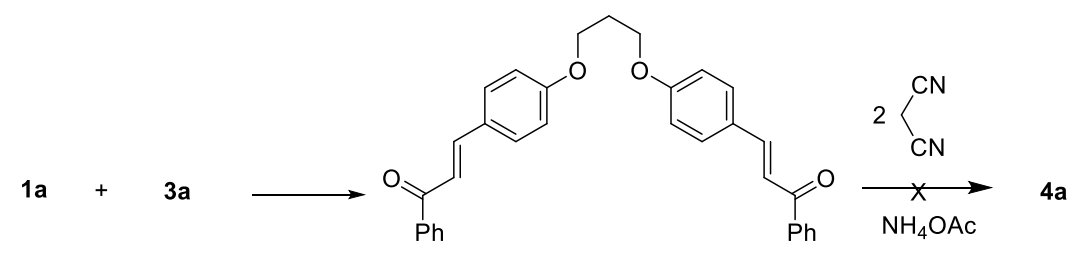

$6 \mathbf{a}$

\section{Scheme 3}

It is noteworthy to mention that attempts to carry out a stepwise reaction through the isolation of the bisarylidenemalononitrile derivative $\mathbf{5 a}$ followed by reaction with acetophenone $\mathbf{3} \mathbf{a}$ in the presence of ammonium acetate were also unsuccessful. Compound $\mathbf{5 a}$ was obtained by Knoevenagel condensation of one mole of bisaldehyde 1a with two moles of malononitrile $\mathbf{2}$ in ethanol in the presence of piperidine as a basic catalyst. The melting point as well as the ${ }^{1} \mathrm{H}$ NMR spectral data of compound $\mathbf{5 a}$ were in agreement to the reported values ${ }^{33,39}$. The ${ }^{1} \mathrm{H}$ NMR spectrum of compound 5 a indicated the presence of singlet signal integrated by two protons at $\delta$ $8.37 \mathrm{ppm}$ assigned to vinyl hydrogenes. In additions, it indicated quintet signal at $\delta 2.25 \mathrm{ppm}$ and triplet signal at $4.29 \mathrm{ppm}$ for methylene protons. The aromatic protons appeared as two doublet at $\delta 7.20$ and $7.96 \mathrm{ppm}$ with the same coupling constant $(J=9 \mathrm{~Hz})$. 
Moreover, the bis-chalcone 6 a was also prepared as previously reported ${ }^{55}$, by the reaction of bis-aldehyde 1a with two moles of acetophenone $\mathbf{3 a}$ in $4 \%$ ethanolic potassium hydroxide solution. Attempts to obtain the bis-pyridine $\mathbf{4 a}$ by the reaction of $\mathbf{6 a}$ with malononitrile $\mathbf{2}$ in the presence of ammonium acetate were also unsuccessful.

In search for an alternative pathway to prepare the target bis-pyridines, our attention turned to utilize $\mathrm{KOH}$ in ethanol as a basic catalyst instead of ammonium acetate. Thus, we studied the reaction of bisarylidenemalononitrile $\mathbf{5 a}$ with acetophenone $\mathbf{3 a}$ in ethanolic potassium hydroxide solution at room temperature. The progress of the reaction was monitored on TLC. The reaction successfully afforded the corresponding bis-pyridine $7 \mathrm{a}$ in a $63 \%$ yield. The bis-chalcone $6 \mathrm{a}$ was also isolated from the reaction mixture as a minor product (Scheme 4).

Similarly, the bis pyridines $\mathbf{7 b} \mathbf{b} \mathbf{c}$ were obtained by reaction of $\mathbf{5 a}$ with the corresponding ketone $\mathbf{3 b}$ and $\mathbf{3 c}$. Although the ${ }^{1} \mathrm{H}$ NMR of the reaction mixtures indicate the presence of few amount of the corresponding chalcones $\mathbf{6 b}$ and $\mathbf{6 c}$, we were not able to isolate pure sample of these compounds (Scheme 4).

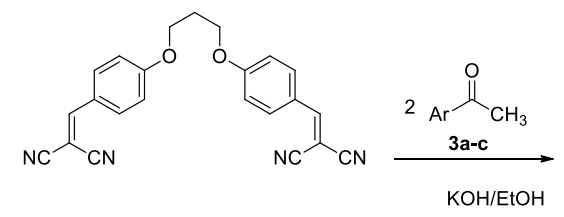

$5 a$

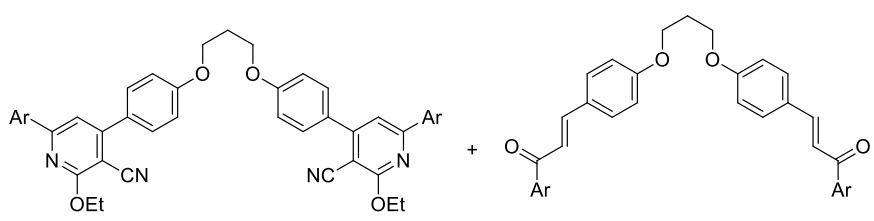

7a, $\mathrm{Ar}=\mathrm{C}_{6} \mathrm{H}_{5^{-}}$

b, $\mathrm{Ar}=4-\mathrm{CH}_{3} \mathrm{C}_{6} \mathrm{H}_{4}$

c, $\mathrm{Ar}=4-\mathrm{ClC}_{6} \mathrm{H}_{4}-$ 6a, $\mathrm{Ar}=\mathrm{C}_{6} \mathrm{H}_{5}$ -

b, $\mathrm{Ar}=4-\mathrm{CH}_{3} \mathrm{C}_{6} \mathrm{H}_{4}$

c, $\mathrm{Ar}=4-\mathrm{ClC}_{6} \mathrm{H}_{4}-$

\section{Scheme 4}

The structure of 7a-c was confirmed by alternative synthesis via stirring a mixture of bis-aldehyde $1 \mathbf{a}$ and acetophenone derivatives $3 a-c$ in ethanol- $\mathrm{KOH}$ mixture to give the corresponding bis-chalcones 6 in $65-80 \%$ yields. Subsequent reaction of $\mathbf{6}$ with malononitrile in ethanol at reflux leads to the formation of compounds 7 as sole products (Scheme 5).

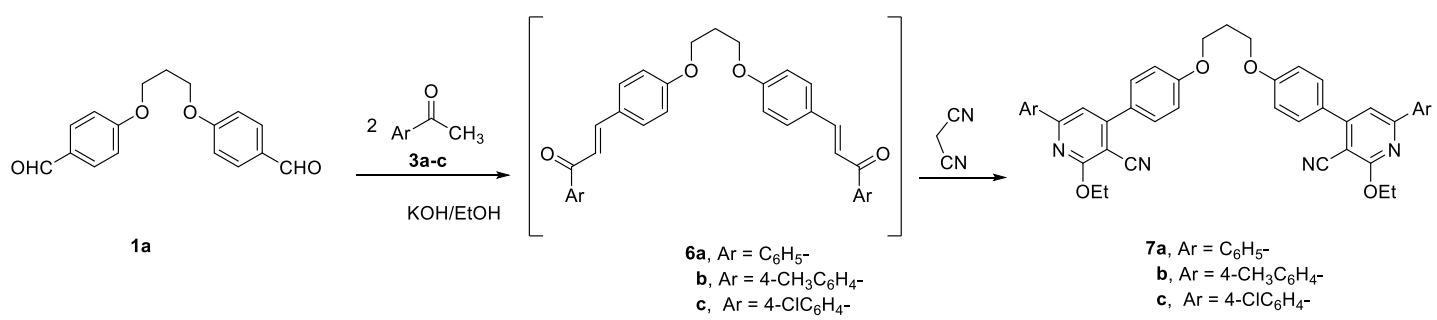

\section{Scheme 5}

Similarly, the bis-pyridine $7 \mathbf{d}$ was obtained in $61 \%$ yield by the reaction of the appropriate bis aldehyde 1b with 4-methylacetophenone $\mathbf{3 b}$ and malononitrile in ethanolic potassium hydroxide solution (Scheme 6). 


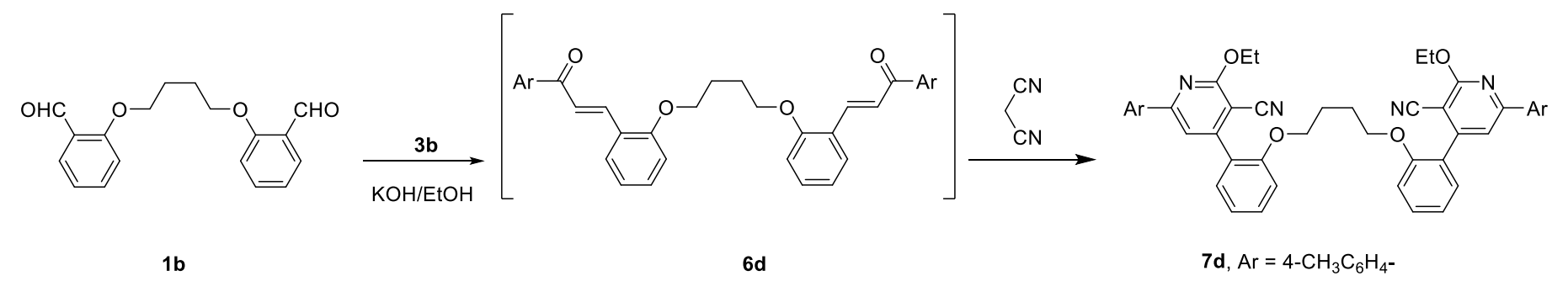

\section{Scheme 6}

Moreover, the structure of $\mathbf{7}$ was confirmed by spectroscopic tools as well as elemental analyses data. The IR spectra of 7 reveal the presence of a nitrile stretching vibration band at $2213-2223 \mathrm{~cm}^{-1}$ region and lack any band assignable for a carbonyl function. The ${ }^{1} \mathrm{H}-\mathrm{NMR}$ spectra of 7 exhibit the presence of the ethoxide moiety ( $\delta=1.46-1.54$ "triplet of $\mathrm{CH}_{3}$ ", $\delta=4.55-4.66$ "quartet for $\mathrm{OCH}_{2}$ ") as well as the pyridine $\mathrm{H}-5$ at $\delta=7.27-7.40$ confirming the cyclized form structure.

The reaction was assumed to take place through addition of $\mathbf{3}$ to the $\beta$-carbon of ylidene $\mathbf{5}$ affording the Michael adduct intermediate $\mathbf{8}$. The latter due to attack of the ethoxide anion at one of the nitrile groups gives intermediate 9 which underwent cyclization followed by dehydration and subsequent dehydrogenation giving finally the isolable product 7 (Scheme 7). The bis-chalcone 6 may be formed via decomposition of 8 through elimination of malononitrile.

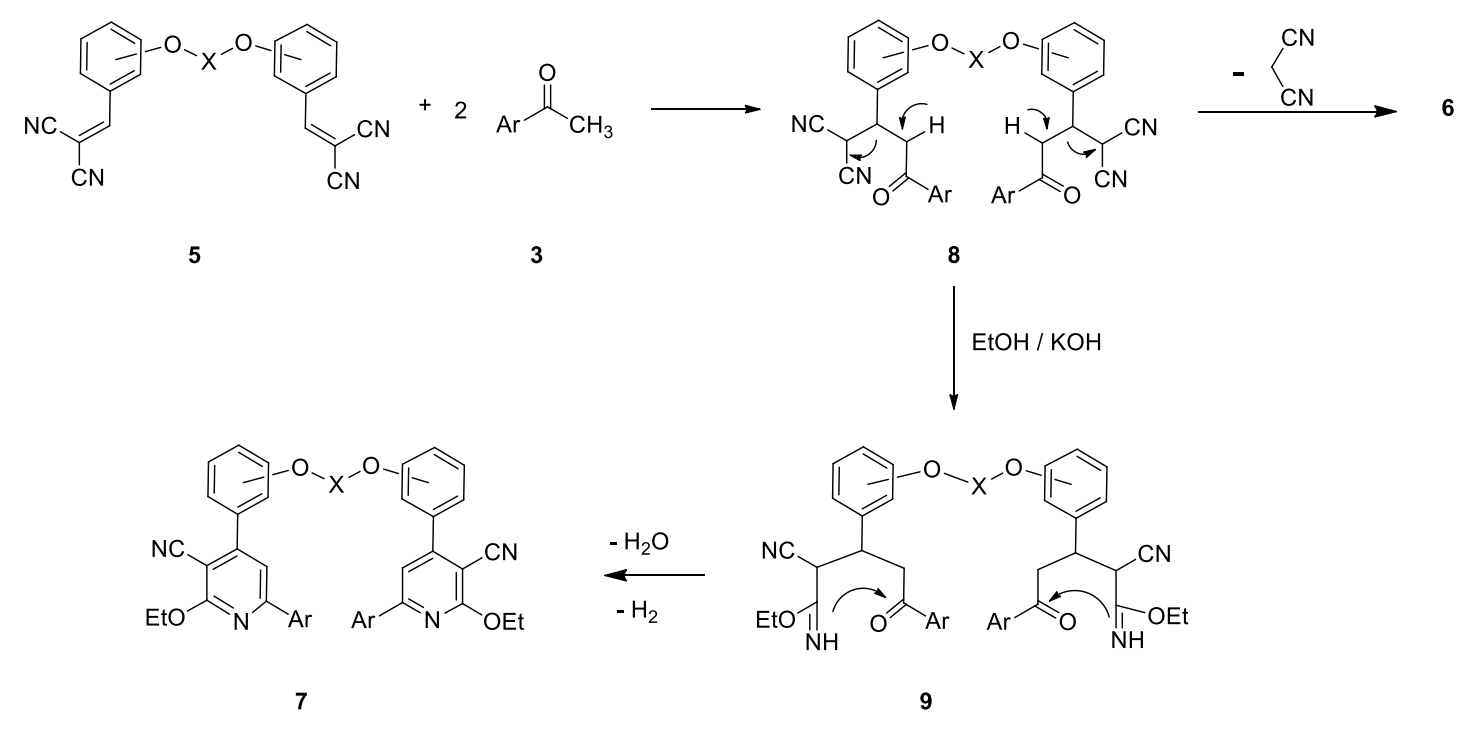

\section{Scheme 7}

Our study was extended to include the synthesis of novel isomeric bis-pyridines $\mathbf{1 2}$ by the reaction of bis acetophenone $\mathbf{1 0}$ with arylidenemalononitriles $\mathbf{1 1}$ in ethanolic potassium hydroxide solution at room temperature. In some cases the bis-chalcones $13^{55}$ were successfully isolated from the reaction mixture as a minor product (Scheme 8). 


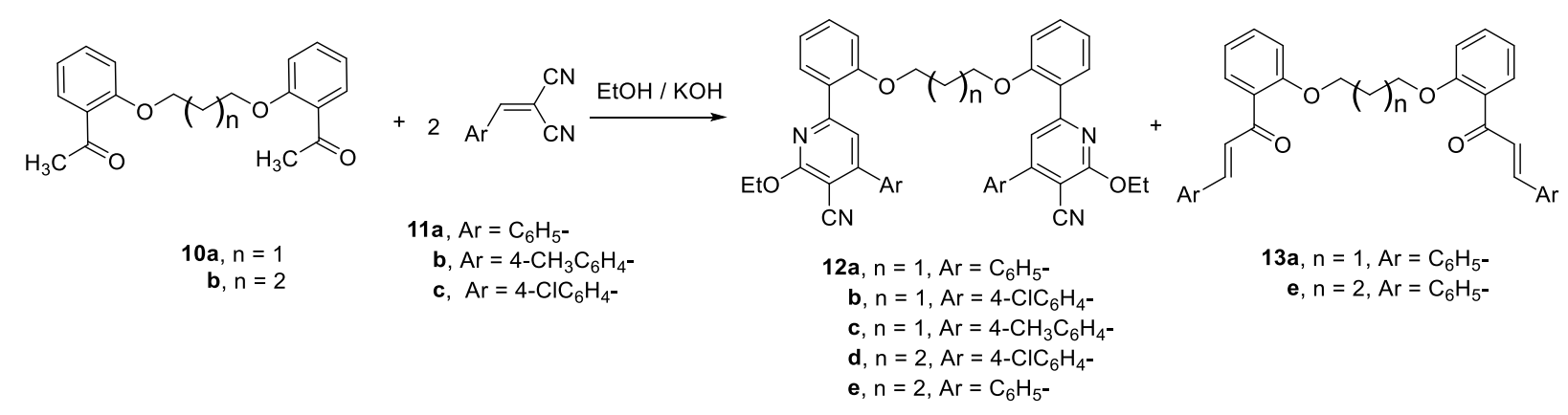

\section{Scheme 8}

The reaction was assumed to take place through addition of $\mathbf{1 0}$ to the $\beta$-carbon of ylidene $\mathbf{1 1}$ affording the Michael adduct intermediate 14. The latter due to attack of the ethoxide anion at one of the nitrile groups gives 15 which underwent cyclization followed by dehydration and subsequent dehydrogenation gives finally the isolable product 12 (Scheme 9).

The bis-chalcone $\mathbf{1 3}$ may be formed via decomposition of $\mathbf{1 4}$ through elimination of malononitrile.
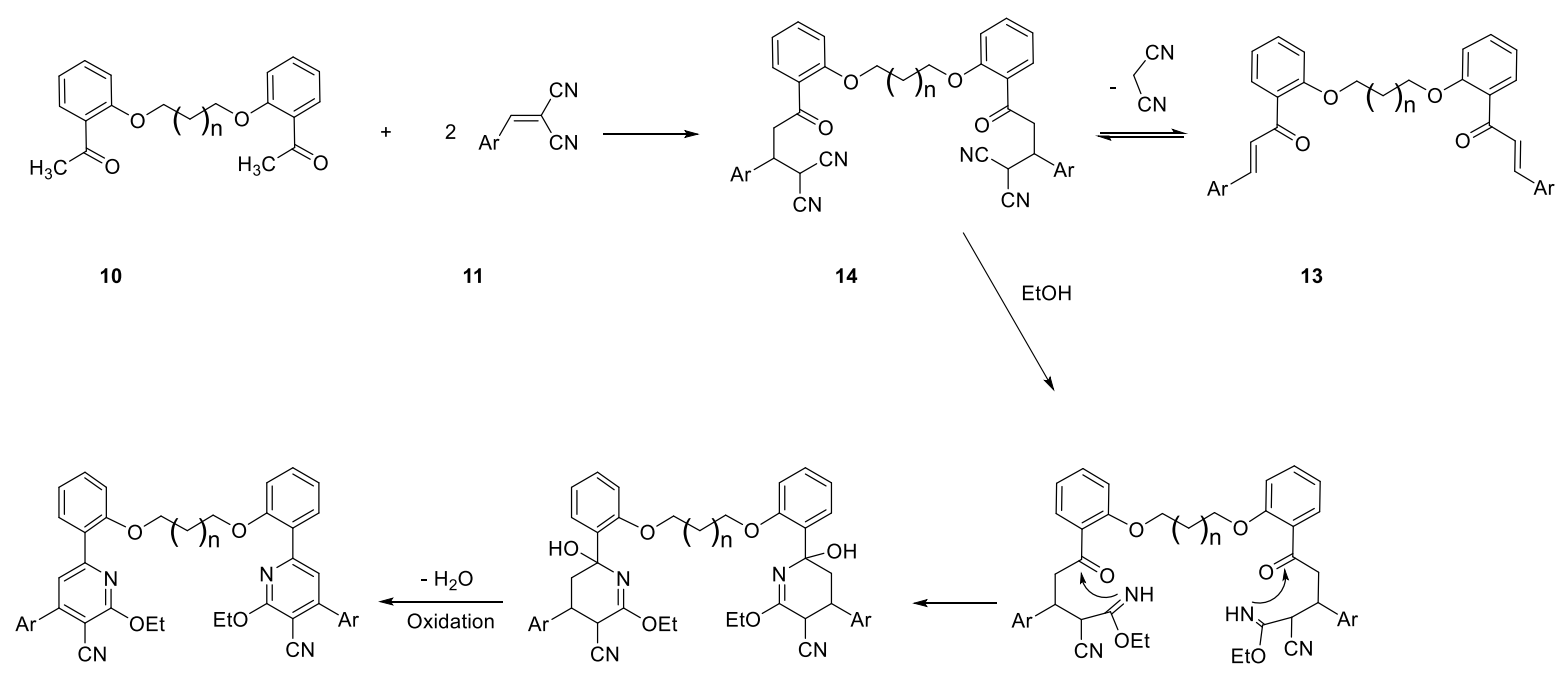

12

16

15

\section{Scheme 9}

The structure of 17 was confirmed by authentication with samples prepared from bis-chalcones 13, obtained in situ from the reaction of bis-acetophenones 10 with the appropriate aldehydes $\mathbf{1 7}$, upon treatment with malononitrile in ethanolic solution containing $\mathrm{KOH}$ (Scheme 10).

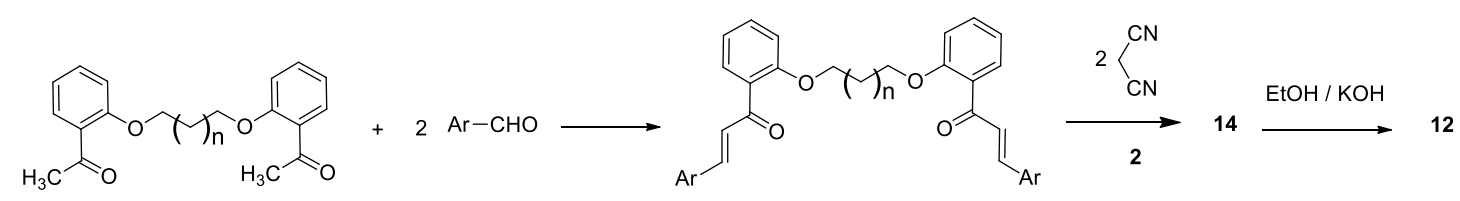


Furthermore, the structure of $\mathbf{1 2}$ was established by spectroscopic and elemental analyses data. The IR spectra reveal a band attributed to the nitrile group at $2213-2223 \mathrm{~cm}^{-1}$ and the absence of a band assignable for the carbonyl group confirming the cyclized form structure. In addition, ${ }^{1} \mathrm{H}$ NMR spectra display the ethoxide protons at $\delta$ 1.46-1.54 "triplet of $\mathrm{CH}_{3}$ " and at $\delta 4.55-4.66$ "quartet for $\mathrm{OCH}_{2}$ ") confirming the involvement of ethoxide function.

\section{Conclusions}

We have developed an efficient synthesis of novel bis(nicotines) which are linked to ether linkage via phenyl groups. Full characterization of these compounds is reported. The newly synthesized compounds were easily prepared in good yields under mild reaction conditions from readily available starting materials. The synthetic strategies used in this work should provide access for novel new bis(functionalized) heterocycles with promising pharmacological and biological activities.

\section{Experimental Section}

General. Melting points were measured with a Stuart melting point apparatus and are uncorrected. The IR spectra were recorded using an FTIR Bruker- vector 22 spectrophotometer as $\mathrm{KBr}$ pellets. The ${ }^{1} \mathrm{H}$ NMR spectra were recorded in DMSO-d6 as solvent on Varian Gemini NMR spectrometer at $400 \mathrm{MHz}$ using TMS as internal standard. Chemical shifts are reported as $\delta$ values in ppm. Mass spectra were recorded with a Shimadzu GCMSQP-1000 EX mass spectrometer in El (70 eV) model or on an AccuTOF-T100LP (JEOL) mass spectrometer in ESI. The elemental analyses were performed at the Micro analytical center, Cairo University. Analytical thin layer chromatography was performed using pre-coated silica gel 60.778 plates (Fluka), and the spots were visualized with UV light at $254 \mathrm{~nm}$. Compounds $5^{33,39}$ and $6^{55}$ have been synthesized as previously reported.

General procedure for 4,4'-((Alkane-1,n-diylbis(oxy))bis(phenylene))bis(2-ethoxy-6-arylnicotinonitriles) (7ad). Method A. A mixture of bisaldehyde derivative (1) $(1 \mathrm{mmol})$ and malononitrile $(2 \mathrm{mmol})$ in absolute ethanol $(20 \mathrm{ml})$ was heated at reflux for $30 \mathrm{~min}$. in the presence of piperidine as a catalyst. The obtained solid was filtered, washed with ethanol and added to a solution of the appropriate acetophenone derivative (3a-c) (2 $\mathrm{mmol})$ in ethanolic $\mathrm{KOH}(20 \mathrm{ml}, 4 \%)$. The reaction mixture was stirred overnight at room temperature. The resulting solid was collected by filteration, and was separated from traces of compounds 6 by preparative thinlayer chromatography using DCM as an eluent where compounds 7a-d showed a value of R.F. equals to 0.920.98. Compounds 7a-d were further purified by recrystallization from DMF/EtOH.

Method B. The appropriate acetophenone derivative (3a-c) $(2 \mathrm{mmol})$ was dissolved in ethanolic $\mathrm{KOH}$ solution $(20 \mathrm{ml}, 4 \%)$ and added to a solution of the corresponding bisaldehyde (1) (1 mmol) in ethanol (10 ml). The reaction mixture was then stirred overnight to afford compounds 6 a-d which were filtered off and washed with ethanol. The solid product was added to malononitrile $(2 \mathrm{mmol})$ in ethanolic $\mathrm{KOH}$ solution $(20 \mathrm{ml}, 4 \%)$. The reaction mixture was then heated at reflux for $2 \mathrm{hr}$. The solid products obtained upon cooling were purified as described in method $A$ to give compounds 7.

4,4'-((Propane-1,3-diylbis(oxy))bis(4,1-phenylene))bis(2-ethoxy-6-phenylnicotinonitrile) (7a). (69\% yield) as colorless crystals, $\mathrm{mp} 220^{\circ} \mathrm{C}$; IR ( $\left.\mathrm{cm}^{-1}\right)$ : $2214(\mathrm{CN}), 1587(\mathrm{C}=\mathrm{N}), 1244$ (C-O-C); ESI-MS: $\mathrm{m} / z$ 695[M+Na+] and 673 $\left[\mathrm{M}+\mathrm{H}^{+}\right] ;{ }^{1} \mathrm{H}-\mathrm{NMR}(300 \mathrm{MHz}, \mathrm{DMSO}): \delta 141-1.46\left(\mathrm{t}, 6 \mathrm{H}, 2 \mathrm{CH}_{3}, J 6.9 \mathrm{~Hz}\right), 2.25-2.29\left(\mathrm{~m}, 2 \mathrm{H}, \mathrm{CH}_{2}, J 6 \mathrm{~Hz}\right), 4.26-4.30$ 
(t, $4 \mathrm{H}, 2 \mathrm{CH}_{2}, J 6 \mathrm{~Hz}$ ), 4.59-4.66 (q, 4H, $\left.2 \mathrm{CH}_{2}, \mathrm{~J}=6.9 \mathrm{~Hz}\right), 7.16-8.24(\mathrm{~m}, 18 \mathrm{H}$, aromatic), 7.75 (s, $2 \mathrm{H}, \mathrm{H}-5 \mathrm{pyridine})$; ${ }^{13} \mathrm{C}-\mathrm{NMR}$ : $\delta 14.32,62.97,94.23,113.28,114.80,115.58,121.45,127.34,128.83,130.21,160.02$. Anal. Calcd for $\mathrm{C}_{43} \mathrm{H}_{36} \mathrm{~N}_{4} \mathrm{O}_{4}$ (672.79): C, 76.77; $\mathrm{H}, 5.39 ; \mathrm{N}, 8.33$. Found: $\mathrm{C}, 77.05 ; \mathrm{H}, 5.22 ; \mathrm{N}, 8.45$.

4,4'-((Propane-1,3-diylbis(oxy))bis(4,1-phenylene))bis(2-ethoxy-6-(p-tolyl)nicotinonitrile) (7b).(66\% yield) as colorless crystals, $\mathrm{mp} 235^{\circ} \mathrm{C}$; IR (cm $\left.{ }^{-1}\right): 2210$ (CN), 1589 (C=N), 1238 (C-O-C); El-MS: $\mathrm{m} / \mathrm{z} 702\left(\mathrm{M}^{+}+2,4.37 \%\right), 700$ $\left(\mathrm{M}^{+}, 19.25 \%\right), 386$ (18.07\%), 369 (27.81\%), 267 (32.14\%), 239 (63.03\%)\%), 105 (100.00\%); ${ }^{1} \mathrm{H}-\mathrm{NMR}(300 \mathrm{MHz}$, DMSO): $\delta$ 140-1.44 (t, 6H, 2CH,$J 7.2 \mathrm{~Hz}), 2.24-2.28\left(\mathrm{~m}, 2 \mathrm{H}, \mathrm{CH}_{2}, J 6 \mathrm{~Hz}\right), 2.36\left(\mathrm{~s}, 6 \mathrm{H}, 2 \mathrm{CH}_{3}\right), 4.25-4.29\left(\mathrm{t}, 4 \mathrm{H}, 2 \mathrm{CH}_{2}\right.$, $J 6 \mathrm{~Hz}), 4.56-4.63\left(\mathrm{q}, 4 \mathrm{H}, 2 \mathrm{CH}_{2}, J 7.2 \mathrm{~Hz}\right), 7.14-8.12\left(\mathrm{~m}, 16 \mathrm{H}\right.$, aromatic), $7.67\left(\mathrm{~s}, 2 \mathrm{H}, \mathrm{H}-5\right.$ pyridine); ${ }^{13} \mathrm{C}-\mathrm{NMR}: \delta$ 14.29, 20.88, 62.86, 64.45, 78.05, 112.80, 114.75, 120.44, 120.46, 127.24, 128.05, 129.41, 130.14, 140.44, 159.96. Anal. Calcd for $\mathrm{C}_{45} \mathrm{H}_{40} \mathrm{~N}_{4} \mathrm{O}_{4}$ (700.82): C, 77.12; $\mathrm{H}, 5.75 ; \mathrm{N}, 7.99$. Found: C, 77.37; H, 5.95; N, 8.32.

4,4'-((Propane-1,3-diylbis(oxy))bis(4,1-phenylene))bis(6-(4-chlorophenyl)-2-ethoxynicotinonitrile) (7c). (63\% yield) as colorless crystals, $\mathrm{mp} 214^{\circ} \mathrm{C}$; IR $\left(\mathrm{cm}^{-1}\right)$ : 2215 (CN), 1587 (C=N), 1242 (C-O-C); ESI-MS: $m / z$ 741[M+H']; ${ }^{1} \mathrm{H}-\mathrm{NMR}(300 \mathrm{MHz}, \mathrm{DMSO}): \delta 140-1.45\left(\mathrm{t}, 6 \mathrm{H}, 2 \mathrm{CH}_{3}, J 6.9 \mathrm{~Hz}\right), 2.24\left(\mathrm{~m}, 2 \mathrm{H}, \mathrm{CH}_{2}\right), 4.25-4.29\left(\mathrm{t}, 4 \mathrm{H}, 2 \mathrm{CH}_{2}, J 5.7 \mathrm{~Hz}\right)$, 4.55-4.61 (q, $\left.4 \mathrm{H}, 2 \mathrm{CH}_{2}, J 6.9 \mathrm{~Hz}\right), 7.15-8.28(\mathrm{~m}, 16 \mathrm{H}$, aromatic), 7.78 (s, 2H, H-5 pyridine). Anal. Calcd for $\mathrm{C}_{43} \mathrm{H}_{34} \mathrm{Cl}_{2} \mathrm{~N}_{4} \mathrm{O}_{4}$ ( 741.66): C, 69.64; $\mathrm{H}, 4.62 ; \mathrm{Cl}, 9.56 ; \mathrm{N}, 7.55$. Found: $\mathrm{C}, 69.77 ; \mathrm{H}, 4.83 ; \mathrm{Cl}, 9.32 ; \mathrm{N}, 7.32$.

4,4'-((Butane-1,4-diylbis(oxy))bis(2,1-phenylene))bis(2-ethoxy-6-(p-tolyl)nicotinonitrile) (7d) (61\% yield) as a colorless crystals, mp $198^{\circ} \mathrm{C}$; IR (cm ${ }^{-1}$ ): 2221 (CN), 1590.02 (C=N), 1250 (C-O-C); ${ }^{1} \mathrm{H}-\mathrm{NMR}(300 \mathrm{MHz}, \mathrm{DMSO}): \delta$ $135-1.40\left(\mathrm{t}, 6 \mathrm{H}, 2 \mathrm{CH}_{3}, J 6.9 \mathrm{~Hz}\right), 1.69\left(\mathrm{t}, 4 \mathrm{H}, 2 \mathrm{CH}_{2}\right), 2.34\left(\mathrm{~s}, 6 \mathrm{H}, 2 \mathrm{CH}_{3}\right), 3.96\left(\mathrm{t}, 4 \mathrm{H}, 2 \mathrm{CH}_{2}\right), 4.51-4.58\left(\mathrm{q}, 4 \mathrm{H}, 2 \mathrm{CH}_{2}, J\right.$ $6.9 \mathrm{~Hz}$ ), 7.02-8.04 (m, 16H, aromatic), 7.60 (s, $2 \mathrm{H}, \mathrm{H}-5$ pyridine). Anal. Calcd for $\mathrm{C}_{46} \mathrm{H}_{42} \mathrm{~N}_{4} \mathrm{O}_{4}$ (686.80): C, 77.29; $H, 5.92 ; N, 7.84$. Found: C, 77.48; H, 5.65; N, 7.53.

General procedure for 6,6'-((alkane-1,n-diylbis(oxy))bis(2,1-phenylene))bis(2-ethoxy-4-Arylnicotinonitriles) (12a-e)._Method A. Bis acetophenone derivative (10) (1 mmol) was dissolved in ethanolic $\mathrm{KOH}$ solution (20 ml, $4 \%)$ and added to a solution of the appropriate arylidenemalononitrile derivative (11a-c) ( $2 \mathrm{mmol}$ ). The reaction mixture was stirred overnight at room temperature. The solid products were collected by filteration, washed by water then by ethanol. The solid product were then separated from traces of compouds $\mathbf{1 3}$ by thin layer chromatography using DCM as an eluent where compounds 12a-e showed a value of R.F. equals to 0.92-0.98. Compounds 12a-e were further purified by recrystallization from ethanol.

Method B. The appropriate bis acetophenone derivative (10) $(1 \mathrm{mmol})$ was dissolved in ethanolic $\mathrm{KOH}$ solution $(20 \mathrm{ml}, 4 \%)$ and added to a solution of the corresponding aromatic aldehyde (17a-c) (2 mmol) in ethanol (10 $\mathrm{ml})$. The reaction mixture was then stirred overnight to afford $13 a-e$. The solid product formed was collected by filteration, and added to malononitrile $(2 \mathrm{mmol})$ in ethanolic $\mathrm{KOH}$ solution $(20 \mathrm{ml}, 4 \%)$. The reaction mixture was then heated at reflux with stirring for $2 \mathrm{hr}$. The resulting solid products upon cooling were purified as described in method $A$ to give compounds 12a-e.

6,6'-((Propane-1,3-diylbis(oxy))bis(2,1-phenylene))bis(2-ethoxy-4-phenylnicotinonitrile) (12a). (71\% yield) as colorless crystals, mp $157^{\circ} \mathrm{C}$; IR (cm $\left.{ }^{-1}\right): 2222$ (CN), $1586(\mathrm{C}=\mathrm{N}), 1234$ (C-O-C); ESI-MS: $\mathrm{m} / z$ 1367 [2M+Na] ${ }^{+}$and $673[\mathrm{M}+\mathrm{H}]^{+} ;{ }^{1} \mathrm{H}-\mathrm{NMR}(300 \mathrm{MHz}, \mathrm{DMSO}): \delta 1.22-1.43\left(\mathrm{t}, 6 \mathrm{H}, 2 \mathrm{CH}_{3}, J 7.2 \mathrm{~Hz}\right), 2.16-2.19\left(\mathrm{~m}, 2 \mathrm{H}, \mathrm{CH}_{2}, J 5.4 \mathrm{~Hz}\right), 4.14-$ $4.18\left(\mathrm{t}, 4 \mathrm{H}, 2 \mathrm{CH}_{2}, J 5.4 \mathrm{~Hz}\right), 4.52-4.59\left(\mathrm{q}, 4 \mathrm{H}, 2 \mathrm{CH}_{2}, J 7.2 \mathrm{~Hz}\right), 6.95-7.52(\mathrm{~m}, 16 \mathrm{H}$, aromatic), $7.68(\mathrm{~s}, 2 \mathrm{H}, \mathrm{H}-5$ pyridine), 7.93-7.96 (dd, $2 \mathrm{H}, \mathrm{H}-3$ phenylene); ${ }^{13} \mathrm{C}-\mathrm{NMR}: \delta 14.29,32.57,62.96,65.07,91.57,112.85,115.22$, 118.11, 120.87, 126.04, 128.12, 128.74, 129.79, 130.77, 130.87, 131.65, 135.93, 155.08, 155.97, 156.48, 163.54. Anal. Calcd for $\mathrm{C}_{43} \mathrm{H}_{36} \mathrm{~N}_{4} \mathrm{O}_{4}$ (672.77): C, 76.77; H, 5.39; N, 8.33. Found: C, 76.35; H, 4.97; N, 8.05. DMSO): $\delta 1.38-1.43\left(\mathrm{t}, 6 \mathrm{H}, 2 \mathrm{CH}_{3}, J 6 \mathrm{~Hz}\right), 2.19\left(\mathrm{~m}, 2 \mathrm{H}, \mathrm{CH}_{2}\right), 4.15-4.15\left(\mathrm{t}, 4 \mathrm{H}, 2 \mathrm{CH}_{2}\right), 4.52-4.59\left(\mathrm{q}, 4 \mathrm{H}, 2 \mathrm{CH}_{2}, J 6\right.$ 
$\mathrm{Hz}$ ), 6.98-7.52 (m, 14H, aromatic), 7.67 (s, 2H, H-5 pyridine), 7.95-7.98 (dd, 2H, H-3 phenylene). Anal. Calcd for $\mathrm{C}_{43} \mathrm{H}_{34} \mathrm{Cl}_{2} \mathrm{~N}_{4} \mathrm{O}_{4}$ (741.66): $\mathrm{C}, 69.64 ; \mathrm{H}, 4.62 ; \mathrm{Cl}, 9.56 ; \mathrm{N}, 7.55$. Found: $\mathrm{C}, 69.41 ; \mathrm{H}, 4.46 ; \mathrm{Cl}, 9.78 ; \mathrm{N}, 7.81$.

6,6'-((Propane-1,3-diylbis(oxy))bis(2,1-phenylene))bis(2-ethoxy-4-(p-tolyl)nicotinonitrile) (12c). (78\% yield) as colorless crystals, mp $170^{\circ} \mathrm{C}$; IR (cm $\left.{ }^{-1}\right): 2222(\mathrm{CN}), 1587$ (C=N), 1235 (C-O-C); ${ }^{1} \mathrm{H}-\mathrm{NMR}$ (300 MHz, DMSO): $\delta 138-$ $1.42\left(\mathrm{t}, 6 \mathrm{H}, 2 \mathrm{CH}_{3}, J 6.9 \mathrm{~Hz}\right), 2.20\left(\mathrm{~m}, 2 \mathrm{H}, \mathrm{CH}_{2}\right), 2.26\left(\mathrm{~s}, 6 \mathrm{H}, 2 \mathrm{CH}_{3}\right), 4.17-4.21\left(\mathrm{t}, 4 \mathrm{H}, 2 \mathrm{CH}_{2}, J 6 \mathrm{~Hz}\right), 4.52-4.56(\mathrm{q}$, $4 \mathrm{H}, 2 \mathrm{CH}_{2}, J 6.9 \mathrm{~Hz}$ ), 7.00-7.40 (m, $14 \mathrm{H}$, aromatic), 7.67 (s, 2H, H-5 pyridine), 7.96-7.98 (d, 2H, H-3 phenylene); ${ }^{13}$ C-NMR: $\delta$ 14.32, 20.74, 63.12, 65.11, 91.33, 112.80, 115.33, 117.89, 120.51, 120.58, 120.86, 125.96, 127.90, 129.28, 130.80, 131.57, 133.03, 133.11, 139.60, 155.02, 155.80, 156.51, 163.60. Anal. Calcd for $\mathrm{C}_{45} \mathrm{H}_{40} \mathrm{~N}_{4} \mathrm{O}_{4}$ (700.82): C, 77.12; H, 5.75; N, 7.99. Found: C, 77.48; H, 5.68; N, 8.19.

6,6'-((Butane-1,4-diylbis(oxy))bis(2,1-phenylene))bis(4-(4-chlorophenyl)-2-ethoxynicotinonitrile) (12d). (59\% yield) as colorless crystals, mp $141^{\circ} \mathrm{C}$; IR $\left(\mathrm{cm}^{-1}\right)$ : 2223 (CN), 1587 (C=N), 1236 (C-O-C); ${ }^{1} \mathrm{H}-\mathrm{NMR}(300 \mathrm{MHz}, \mathrm{DMSO})$ : $\delta$ 141-1.46 (t, $\left.6 \mathrm{H}, 2 \mathrm{CH}_{3}, J 6.9 \mathrm{~Hz}\right), 1.81\left(\mathrm{t}, 4 \mathrm{H}, 2 \mathrm{CH}_{2}\right), 3.94\left(\mathrm{t}, 4 \mathrm{H}, 2 \mathrm{CH}_{2}\right), 4.57-4.64\left(\mathrm{q}, 4 \mathrm{H}, 2 \mathrm{CH}_{2}, J 6.9 \mathrm{~Hz}\right), 7.04-$ $7.51\left(\mathrm{~m}, 14 \mathrm{H}\right.$, aromatic), 7.63 (s, 2H, H-5 pyridine), 8.07-8.10 (dd, 2H, H-3 phenylene); ${ }^{13} \mathrm{C}-\mathrm{NMR}: \delta 14.27,26.55$, 63.02, 67.68, 91.10, 112.50, 114.97, 117.89, 120.43, 120.70, 125.31, 128.39, 129.69, 130.80, 131.83, 134.41, 134.65, 153.57, 155.70, 156.97, 164.24. Anal. Calcd for $\mathrm{C}_{44} \mathrm{H}_{36} \mathrm{Cl}_{2} \mathrm{~N}_{4} \mathrm{O}_{4}$ (755.69): C, 69.93; $\mathrm{H}, 4.80 ; \mathrm{Cl}, 9.38 ; \mathrm{N}$, 7.41. Found: $\mathrm{C}, 69.71 ; \mathrm{H}, 4.68 ; \mathrm{Cl}, 9.02 ; \mathrm{N}, 7.76$.

6,6'-((Butane-1,4-diylbis(oxy))bis(2,1-phenylene))bis(2-ethoxy-4-phenylnicotinonitrile) (12e) (69\% yield) as colorless crystals, $\mathrm{mp} 152^{\circ} \mathrm{C}$; IR $\left(\mathrm{cm}^{-1}\right)$ : $2221(\mathrm{CN}), 1583(\mathrm{C}=\mathrm{N}), 1232$ (C-O-C); EI-MS: $\mathrm{m} / z 686\left(\mathrm{M}^{+}, 3.62 \%\right), 643$ (11.27\%), 316 (66.51\%), 301 (57.07\%), 55 (100\%); ${ }^{1} \mathrm{H}-\mathrm{NMR}$ (300 MHz, DMSO): $\delta$ 140-1.45 (t, 6H, 2CH3, J 7.2 Hz), 1.81(t, $\left.4 \mathrm{H}, 2 \mathrm{CH}_{2}\right), 3.95\left(\mathrm{t}, 4 \mathrm{H}, 2 \mathrm{CH}_{2}\right), 4.55-4.62\left(\mathrm{q}, 4 \mathrm{H}, 2 \mathrm{CH}_{2}, \mathrm{~J} 7.2 \mathrm{~Hz}\right), 7.04-7.50(\mathrm{~m}, 14 \mathrm{H}$, aromatic), $7.69(\mathrm{~s}, 2 \mathrm{H}$, $\mathrm{H}-5$ pyridine), 8.04-8.07 (dd, $2 \mathrm{H}, \mathrm{H}-3$ phenylene). Anal. Calcd for $\mathrm{C}_{44} \mathrm{H}_{38} \mathrm{~N}_{4} \mathrm{O}_{4}$ (686.80): C, 76.95; $\mathrm{H}, 5.58 ; \mathrm{N}, 8.16$. Found: $C, 76.72 ; \mathrm{H}, 5.35 ; \mathrm{N}, 8.44$.

\section{Acknowledgements}

Elwahy and Abdelhamid gratefully acknowledge the Alexander von Humboldt Foundation for a research fellowship.

\section{References}

1. Allais, C.; Grassot, J.-M.; Rodriguez, J.; Constantieux, T. Chem. Rev. 2014, 114 (21), 10829. https://doi.org/10.1021/cr500099b

2. Henry, G. D. Tetrahedron 2004, 60 (29), 6043. https://doi.org/10.1016/i.tet.2004.04.043

3. Michael, J. P. Nat. Prod. Rep. 2005, 22 (5), 627. https://doi.org/10.1039/b413750g

4. Jayasinghe, L.; Jayasooriya, C. P.; Hara, N.; Fujimoto, Y. Tetrahedron Lett. 2003, 44 (49), 8769. https://doi.org/10.1016/j.tetlet.2003.09.177

5. Kubota, T.; Nishi, T.; Fukushi, E.; Kawabata, J.; Fromont, J.; Kobayashi, J. Tetrahedron Lett. 2007, 48 (29), 4983.

https://doi.org/10.1016/i.tetlet.2007.05.121 
6. Swainston Harrison, T.; Scott, L. J. Drugs 2005, 65 (16), 2309.

https://doi.org/10.2165/00003495-200565160-00010

7. Deininger, M. W. N.; Druker, B. J. Pharmacol. Rev. 2003, 55 (3), 401. https://doi.org/10.1124/pr.55.3.4

8. P.Carlson, G. Toxicol. Lett. 1996, 85 (3), 173. https://doi.org/10.1016/0378-4274(96)03660-0

9. Pryde, D. C.; Dalvie, D.; Hu, Q.; Jones, P.; Obach, R. S.; Tran, T.-D. J. Med. Chem. 2010, 53 (24), 8441. https://doi.org/10.1021/jm100888d

10. Konda, S. G.; Khedkar, V. T.; Dawane, B. J. Chem. Pharm. Res. 2010, 2 (1), 187.

11. Mungra, D. C.; Patel, M. P.; Patel, R. G. Arkivoc 2009, (xiv), 64. http://dx.doi.org/10.3998/ark.550190.010.e06

12. Vyas, D. H.; Tala, S. D.; Akbari, J. D.; Dhaduk, M. F.; Joshi, K. A.; Joshi, H. S. Indian J. Chem. 2009, 48, 833.

13. Gholap, A. R.; Toti, K. S.; Shirazi, F.; Kumari, R.; Bhat, M. K.; Deshpande, M. V; Srinivasan, K. V. Bioorg. Med. Chem. 2007, 15 (21), 6705. https://doi.org/10.1016/i.bmc.2007.08.009

14. Bekhit, A. A.; Baraka, A. M. Eur. J. Med. Chem. 2005, 40 (12), 1405. https://doi.org/10.1016/i.ejmech.2005.06.005

15. Murata, T.; Shimada, M.; Sakakibara, S.; Yoshino, T.; Kadono, H.; Masuda, T.; Shimazaki, M.; Shintani, T.; Fuchikami, K.; Sakai, K.; et al. Bioorg. Med. Chem. Lett. 2003, 13 (5), 913. https://doi.org/10.1016/S0960-894X(02)01046-6

16. Hammam, A. E.; El-Salam, O. I. A.; Mohamed, A. M.; Abdel Hafez, N. Indian J. Chem. Sect. B 2005, 44B, 1887.

17. Shi, F.; Tu, S.; Fang, F.; Li, T. Arkivoc 2005, i, 137. http://dx.doi.org/10.3998/ark.550190.0006.114

18. Ren, Q.; Mo, W.; Gao, L.; He, H.; Gu, Y. J. Heterocycl. Chem. 2010, 47 (1), 171. https://doi.org/10.1002/ihet.296

19. Zhang, W.; Chen, Y.; Chen, W.; Liu, Z.; Li, Z. J. Agric. Food Chem. 2010, 58 (10), 6296. https://doi.org/10.1021/jf100645y

20. Ali, T. E. S. Eur. J. Med. Chem. 2009, 44 (11), 4385. https://doi.org/10.1016/i.ejmech.2009.05.031

21. Bull, J. A.; Mousseau, J. J.; Pelletier, G.; Charette, A. B. Chem. Rev. 2012, 112 (5), 2642. https://doi.org/10.1021/cr200251d

22. Ranu, B. C.; Jana, R.; Sowmiah, S. J. Org. Chem. 2007, 72 (8), 3152. https://doi.org/10.1021/jo070015g

23. Wei, H.; Li, Y.; Xiao, K.; Cheng, B.; Wang, H.; Hu, L.; Zhai, H. Org. Lett. 2015, 17 (24), 5974. https://doi.org/10.1021/acs.orglett.5b02903

24. Ye, F.; Haddad, M.; Ratovelomanana-Vidal, V.; Michelet, V. Org. Lett. 2017, 19 (5), 1104. https://doi.org/10.1021/acs.orglett.7b00130

25. Candeias, N. R.; Montalbano, F.; Cal, P. M. S. D.; Gois, P. M. P. Chem. Rev. 2010, 110 (10), 6169. https://doi.org/10.1021/cr100108k

26. Isambert, N.; Duque, M. del M. S.; Plaquevent, J.-C.; Génisson, Y.; Rodriguez, J.; Constantieux, T. Chem. Soc. Rev. 2011, 40 (3), 1347. https://doi.org/10.1039/COCS00013B 
27. Shiri, M. Chem. Rev. 2012, 112 (6), 3508.

https://doi.org/10.1021/cr2003954

28. Dömling, A.; Wang, W.; Wang, K. Chem. Rev. 2012, 112 (6), 3083. https://doi.org/10.1021/cr100233r

29. Brauch, S.; van Berkel, S. S.; Westermann, B. Chem. Soc. Rev. 2013, 42 (12), 4948. https://doi.org/10.1039/c3cs35505e

30. Ghozlan, S. A. S.; Mohamed, M. H.; Abdelmoniem, A. M.; Abdelhamid, I. A. Arkivoc 2009, (x), 302. http://dx.doi.org/10.3998/ark.5550190.0010.a27

31. Abdelhamid, I. A.; Mohamed, M. H.; Abdelmoniem, A. M.; Ghozlan, S. A. S. Tetrahedron 2009, 65 (48), 10069. https://doi.org/10.1016/j.tet.2009.09.081

32. Ghozlan, S. A. S.; Abdelhamid, I. A.; Hassaneen, H. M.; Elnagdi, M. H. J. Heterocycl. Chem. 2007, 44 (1), 105.

https://doi.org/10.1002/jhet.5570440118

33. Abdella, A. M.; Moatasim, Y.; Ali, M. A.; Elwahy, A. H. M.; Abdelhamid, I. A. J. Heterocycl. Chem. 2017, 54 (3), 1854.

https://doi.org/10.1002/ihet.2776

34. Abdella, A. M.; Elwahy, A. H. M.; Abdelhamid, I. A. Curr. Org. Synth. 2016, 13 (4), 601. https://doi.org/10.2174/1570179413999151211115100

35. Abdelmoniem, A. M.; Ghozlan, S. A. S.; Butenschön, H.; Abdelhamid, I. A. J. Heterocycl. Chem. 2017, 54 (1), 473.

https://doi.org/10.1002/ihet.2606

36. Abdelmoniem, A. M.; Salaheldin, T. A.; Abdelhamid, I. A.; Elwahy, A. H. M. J. Heterocycl. Chem. 2017, 54, 2670.

https://doi.org/10.1002/jhet.2867

37. Abdelhamid, I. A.; Darwish, E. S.; Nasra, M. A.; Abdel-Gallil, F. M.; Fleita, D. H. Synthesis 2010, No. 7, 1107. https://doi.org/10.1055/s-0029-1219235

38. Al-Awadi, N. A.; Ibrahim, M. R.; Abdelhamid, I. A.; Elnagdi, M. H. Tetrahedron 2008, 64 (35), 8202. https://doi.org/10.1016/j.tet.2008.06.026

39. Salama, S. K.; Darweesh, A. F.; Abdelhamid, I. A.; Elwahy, A. H. M. J. Heterocycl. Chem. 2017, 54 (1), 305. https://doi.org/10.1002/ihet.2584

40. Sanad, S. M. H.; Kassab, R. M.; Abdelhamid, I. A.; Elwahy, A. H. M. Heterocycles 2016, 92 (5), 910. https://doi.org/10.3987/COM-16-13441

41. Elwahy, A. H. M.; Shaaban, M. R. Curr. Org. Synth. 2015, 10 (3), 425. https://doi.org/10.2174/1570179411310030007

42. Shaaban, M. R.; Elwahy, A. H. M. Curr. Org. Synth. 2015, 11 (4), 471. https://doi.org/10.2174/15701794113106660076

43. Abdella, A. M.; Elwahy, A. H. M.; Abdelhamid., I. A. Curr. Org. Synth. 2016, 13 (4), 601. https://doi.org/10.2174/1570179413999151211115100

44. Shaaban, M. R.; Elwahy, A. H. M. J. Heterocycl. Chem. 2012, 49 (3), 640. https://doi.org/10.1002/jhet.861

45. Abdelmoniem, A. M.; Ghozlan, S. A. S.; Abdelmoniem, D. M.; Elwahy, A. H. M.; Abdelhamid, I. A. J. Heterocycl. Chem. 2017, 54 (5), 2844.

https://doi.org/10.1002/jhet.2890 
46. Elwahy, A. H. M.; Abbas, A. A. Synth. Commun. 2000, 30 (16), 2903. https://doi.org/10.1080/00397910008087441

47. Salem, M. E.; Darweesh, A. F.; Mekky, A. E. M.; Ahmad M. Farag, A.; Elwahy, and A. H. M. J. Heterocycl. Chem. 2017, 54, 226.

48. Abdelmoniem, A. M.; Elwahy, A. H. M.; Abdelhamid, I. A. Arkivoc 2016, iii, 304. https://doi.org/10.3998/ark.5550190.0017.324

49. Sayed, O. M.; Mekky, A. E. M.; Farag, A. M.; Elwahy, A. H. M. J. Heterocycl. Chem. 2016, 53, 1113. https://doi.org/10.1002/jhet.2373

50. Elwahy, A. H. M.; Abbas, A. A. Synth. Commun. 2000, 30 (16), 2903. https://doi.org/10.1080/00397910008087441

51. Salem, M. E.; Darweesh, A. F.; Farag, A. M.; Elwahy, A. H. M. Tetrahedron 2016, 72 (5), 712. https://doi.org/10.1016/i.tet.2015.12.024

52. Sayed, O. M.; Mekky, A. E. M.; Farag, A. M.; Elwahy, A. H. M. J. Sulfur Chem. 2014, 36 (2), 124. https://doi.org/10.1080/17415993.2014.975131

53. Elwahy, A. H. M.; Shaaban, M. R. Curr. Org. Synth. 2015, 11 (6), 835. https://doi.org/10.2174/157017941106141023114039

54. Elwahy, A. H. M.; Masaret, G. S. J. Heterocycl. Chem. 2007, 44 (6), 1475. https://doi.org/10.1002/jhet.5570440636

55. Elwahy, A. H. M. J. Chem. Res. 1999, No. 10, (S) 602. https://doi.org/10.1039/a904716f 